\title{
Synchronous Primary Adenocarcinoma and
} Gastrointestinal Stromal Tumor in the Stomach

\section{Midenin Senkron Gastrointestinal Stromal Tümör ve Primer Adenokarsinomu}

\author{
Hamza Çınar, Koray Topgül*, Tuğrul Kesicioğlu**, Bilge Can***, Bülent Koca****, \\ illhan Karabıçak, Gökhan Selçuk Özbalcı \\ Ondokuz Mayıs University, Faculty of Medicine, Department of Surgery, Samsun, Turkey \\ ${ }^{*}$ Medikal Park Hospital, Department of Surgery, Samsun, Turkey \\ **Oltu State Hospital, Department of Surgery, Erzurum, Turkey \\ $* * *$ Ondokuz Mayıs University, Faculty of Medicine, Department of Pathology, Samsun, Turkey \\ $* * * *$ Korgan State Hospital, Department of Surgery, Ordu, Turkey
}

\begin{abstract}
Gastrointestinal stromal tumors (GISTs) and adenocancers are distinct neoplasms originating from different cell layers. Synchronous development of a GIST and adenocancer in the stomach is extremely rare and that have been reported only as case reports in the literature. In this paper, we report the case of a 76-year-old female patient who had synchronous gastric tumors and, analyze synchronous tumors of the stomach. (Haseki Tip Bülteni 2014; 52: 50-2)
\end{abstract}

Key Words: Synchronous tumor, gastric adenocarcinoma, stromal tumor

\section{Introduction}

Gastrointestinal stromal tumors (GISTs) and adenocancers are distinct neoplasms originating from different cell layers (1). GIST is the most common gastrointestinal mesenchymal tumor, accounting for 3\% of malignant gastric tumors. Gastric adenocarcinomas account for $95 \%$ of all malignant gastric tumors. Synchronous development of a GIST and gastric tumors is extremely rare (2). We present a case of synchronous occurrence of gastric adenocarcinoma and stromal tumor.

\section{Case}

A 76-year-old female patient, who had the complaints of increasing nausea, vomiting and abdominal pain after meals in the last three months, had lost $8 \mathrm{~kg}$ weight in the last month. Laboratory examinations were normal on admission. An ulcerovegetating mass surrounding the gastric cardia circumferentially was detected during the upper gastrointestinal endoscopy. Imprints of a biopsy of the mass revealed an intestinal type adenocarcinoma. An abdominal tomography scan showed no invasion to any area outside the stomach. During the surgery, it was observed that the mass in the cardia was spread up to the
Address for Correspondence/Yazışma Adresi: Hamza Çınar

Ondokuz Mayıs University, Medicine Faculty, Department of Surgery, Samsun, Turkey Phone: +90 3623121919 E-mail: drhamzacinar@gmail.com

Received/Geliş Tarihi: 20 May 2013 Accepted/Kabul Tarihi: 20 July 2013
The Medical Bulletin of Haseki Training and Research Hospital, published by Galenos Publishing. Haseki Tip Bülteni,

Galenos Yayınevi tarafindan basılmıştır. 
abdominal esophagus as well as the gastric serosa, besides, a nodular lesion was detected which was estimated to be a well-circumscribed GIST measuring approximately $3 \mathrm{~cm}$ in diameter, adjacent to the second segment of the liver. Total gastrectomy, esophagojejunostomy and jejunojejunostomy were performed.

Pathological examination of the specimen from the stomach obtained by total gastrectomy revealed an ulcerovegetating mass measuring $3.5 \times 2 \times 1.3 \mathrm{~cm}$ in diameter, off-white colored and solid on the cut-surface. In addition, on the anterior serosal surface of the gastric corpus, there was a semi-solid nodular mass with a smooth surface and the dimensions of $2.5 \times 2.5 \times 2 \mathrm{~cm}$. Histological examination showed that the mass detected in the cardia was a welldifferentiated adenocarcinoma of intestinal type (Figure 1). There were lymphovascular and perineural invasion. Lymph node metastasis from adenocarcinoma was detected in four of the 21 dissected regional lymph nodes. Tumor implants were observed in the lesser curvature fat tissue. The nodular mass observed in the serosa characterized as mesenchymal tumor consisted of fusiform cells with no increased mitotic activity, necrosis, and prominent pleomorphism, therefore, it was reported as "gastrointestinal stromal tumor with very low risk of malignancy" (Figure 2). Since the general condition of the patient was poor, chemotherapy was not administrated for gastric adenocarcinoma. Any other treatments for GIST were not considered because of the total excision and low risk potential.

\section{Discussion}

The term GIST was introduced by Mazur and Clark in 1983 (3). GISTs are believed to originate from the stem celllike precursors of the interstitial cells of Cajal (4). Although rare, with an annual incidence of approximately 10-15 cases per 1 million individuals, GISTs are the most common mesenchymal tumors of the gastrointestinal tract (5). They may occur in any part of the gastrointestinal track, from the lower esophagus to the anus. The most common sites are the stomach $(60 \%)$, jejunum and ileum (30\%), duodenum $(5 \%)$, and colorectum $(<5 \%)$ while a few cases $(<1 \%)$ have been reported in the esophagus and appendix (6).

GISTs often present with non-specific symptoms, such as nausea, vomiting, abdominal pain, gastrointestinal bleeding, and metastatic diseases. Bleeding is considered as the most common presentation of the clinical course (7). Symptoms depend on tumor size and location. In our case, the GIST was totally asymptomatic. Ulcerations seem to be related with the size of GISTs. The size and mitotic score are considered as important diagnostic criteria and prognostic predictive indicators (7).

GISTs are resistant to chemotherapy. Radiotherapy and surgery is the initial treatment for GISTs. In general,

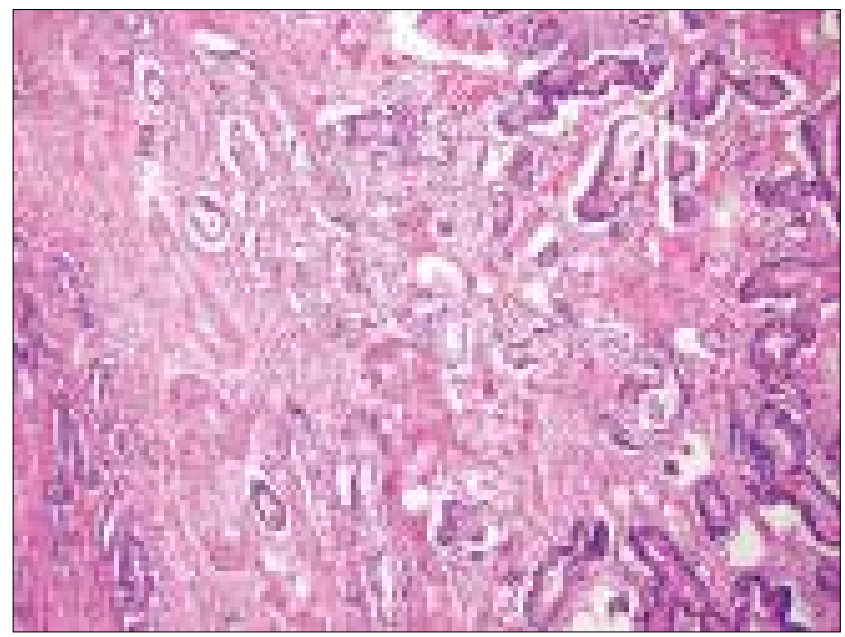

Figure 1. Adenocarcinoma in the cardia (x100, hematoxylin \& eosin)

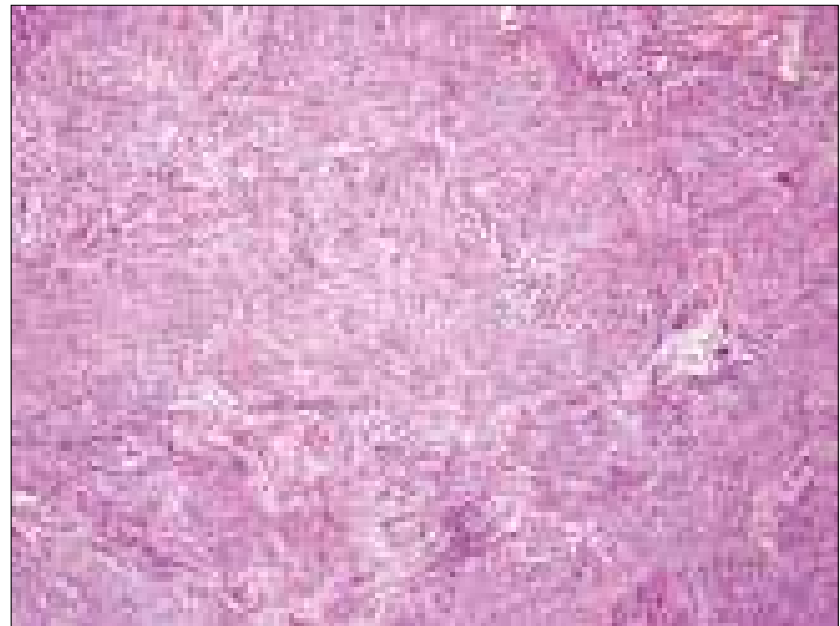

Figure 2. Serosal gastrointestinal stromal tumor (x100, hematoxylin \& eosin)

complete excision is the main treatment. Small GISTs $(<5 \mathrm{~cm})$ can be treated by gastric wedge resection while larger tumors may require a subtotal or total gastrectomy. Patients with unresectable tumors or with metastatic disease are treated with KIT/PDGFRA tyrosine kinase inhibitors. Metastases may develop in the abdominal cavity, liver, bones, soft tissues, skin, lymph nodes and the lungs after 10-15 years of primary surgery. Patients with advanced GIST, which progress rapidly and result in organ destruction, have a poor prognosis $(8,9)$.

Two or more primary tumors coexisting in the same patient are called synchronous tumors and two histologically distinct neoplasms developing concurrently in the same anatomic location are called collision tumors (10). Although the coexistence of GISTs with other neoplasms has been widely addressed in the literature, only a few cases of synchronous occurrence of gastric adenocarcinoma and GISTs are reported. Maiorana 
et al. reported a series of five cases in which there was simultaneous association of stromal tumors with adenocarcinoma (11). The most common secondary neoplasms of GISTs are colorectal cancer, prostate cancer, and neoplasms derived from lymphoid tissue (12).

Synchronous development of a GIST and a gastric tumor is usually detected during surgery or histopathological examination of a biopsy specimen. Small GISTs arising from submucosal and muscular layers may go unnoticed at endoscopic or radiological assessments. The prognosis of these patients is similar to that of patients with only gastric cancers (13).

There are a number of hypotheses suggesting if the concurrent presence of epithelial tumors and stromal gastric tumors is just a coincident or they are casually connected. The interaction of a single carcinogenic agent with two neighboring tissues may induce development of tumors of different histological types in the same organ. N-methyl$\mathrm{N}^{\prime}$-nitrosoguanidine can induce gastric adenocarcinoma after oral administration in rats. If combined with agents altering the gastric mucosal barrier, such as non-steroidal anti-inflammatory drugs, leiomyosarcomas may develop in association with the epithelial tumors. However, there is no evidence showing that these compounds play an important role in the development of human gastric cancer. We anticipate that the stomach may have been influenced by the same unknown carcinogen, resulting in simultaneous proliferation of different cell lines (epithelial and stromal cells) especially in the elderly. A potential pluripotent stem cell could also be the initial target of the carcinogen or causal influence, however, further studies are needed to clarify these possibilities (14). Maiorana et al. suggested that gene mutations might underlie tumour predisposition in patients harbouring a double gastric neoplasia (11).

\section{Conclusion}

In summary, the synchronous occurrence of GIST and adenocarcinoma is an uncommon finding and little is known about this issue. Investigating the molecular alterations in such cases may reveal the etiology of synchronous tumors and further studies are needed for better understanding the clinical course of this coexistence and its effect on prognosis.

\section{Kaynaklar}

1. Liu SW, Chen GH, Hsieh PP. Collision tumor of the stomach: a case report of mixed gastrointestinal stromal tumor and adenocarcinoma. J Clin Gastroenterol 2002;35:332-4.

2. Uchiyama S, Nagano M, Takahashi N, et al. Synchronous adenocarcinoma and gastrointestinal stromal tumors of the stomach treated laparoscopically. Int J Clin Oncol 2007; 12:478-81.

3. Mazur MT, Clark HB. Gastric stromal tumors. Reappraisal of histogenesis. Am J Surg Pathol 1983;7:507-19.

4. Miettinen M, Lasota J. Gastrointestinal stromal tumours: pathology and prognosis at different sites. Semin Diagn Pathol 2006;23:70-83.

5. Perez EA, Livingstone AS, Franceschi $D$, et al. Current incidence and outcomes of gastrointestinal mesenchymal tumors including gastrointestinal stromal tumors. J Am Coll Surg 2006;202:623-29

6. Judson I. Gastrointestinal stromal tumours (GIST): Biology and treatment. Ann Oncol 2002; 13: 287-9.

7. Yamada T. Textbook of Gastroenterology. 4th ed. Philadelphia: Lippincott Williams \& Wilkins, 2003; 1434

8. Buchdunger $\mathrm{E}$, Cioffi $\mathrm{CL}$, Law $\mathrm{N}$, et al. Abl protein-tyrosine kinase inhibitor STI571 inhibits in vitro signal transduction mediated by c-kit and platelet-derived growth factor receptors. J Pharmacol Exp Ther 2000; 295: 139-45

9. Villias C, Gourgiotis S, Veloudis G, et al. Synchronous early gastric cancer and gastrointestinal stromal tumor in the stomach of a patient with idiopathic thrombocytopenic purpura. Journal of Digestive Diseases 2008; 9; 104-7

10. Mou YP, Xu XW, Xie K, et al. Laparoscopic wedge resection of synchronous gastric intraepithelial neoplasia and stromal tumor: A case report. World J Gastroenterol 2010;16:5005-8

11. Maiorana A, Fante $R$, Cesinaro AM, et al. Synchronous occurrence of epithelial and stromal tumors in the stomach. A report of 6 cases. Arch Pathol Lab Med 2000; 124:682-6.

12. Liszka L, Zielinska-Pajak E, Pajak J, et al. Coexistence of gastrointestinal stromal tumors with other neoplasms. J Gastroenterol 2007;42:641-64.

13. Strofilas A, Dalianoudis IG, Lagoudianakis EE, et al. Collision tumour of the stomach with a cancer to cancer metastasis: a case report. Cases J 2008;1:63.

14. Lee FY, Jan YJ, Wang J, et al. Synchronous gastric gastrointestinal stromal tumor and signet-ring cell adenocarcinoma: A Case Report. Int J Surg Pathol 2007;15:397. 